\title{
Truth, Superassertability, and Conceivability
}

\section{Glen A. Hoffmann}

Ryerson University

Hoffmann, G. A. (2008). Truth, superassertability, and conceivability. Journal of Value Inquiry, 42(3), 287-299.

doi:10.1007/s10790-008-9125-9

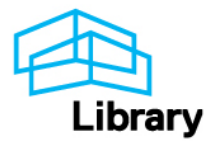




\title{
Truth, Superassertability, and Conceivability \\ Glen Hoffmann
}

\begin{abstract}
The superassertability theory of truth, inspired by Crispin Wright (1992, 2003), holds that a statement is true iff it is superassertable in the following sense: it possesses warrant that cannot be defeated by any improvement of our information. While initially promising, the superassertability theory of truth is vulnerable to a persistent difficulty highlighted by Van Cleve (1996) and Horgan (1995) but not properly fleshed out: it is formally/informally illegitimate in a similar sense that unsophisticated epistemic theories of truth (theories that identify truth with bare warranted assertability) are widely acknowledged to be. Sustained analysis reveals that the unrestricted formal/informal legitimacy argument is firmly grounded in first-person conceivability/possibility evidence.
\end{abstract}

\section{§1 Introduction}

Epistemic theories of truth identify truth with some positive epistemic status of truth bearers. Sophisticated versions of this theory identify truth with some kind of idealization of warranted assertability. ${ }^{1}$ The proposal is that a statement is true iff it is warrantedly assertable in ideal epistemic conditions A, B, C..., where A, B, C... signify some sort of projection of current standards of rational acceptability. For example, it has been proposed that a statement is true iff it is warrantedly assertable 'at the end of inquiry' (Putnam, 1981 and Ellis, 1990), 'after fruitful deliberation' (Peirce, 1931 and Misak, 1991), 'after all the relevant evidence is in' (Alston, 1996 (rejected)), and the like.

\footnotetext{
${ }^{1}$ Unsophisticated versions identify truth with bare warranted assertability. Proponents of an unsophisticated epistemic theory of truth have included James (1975, p. 97) and Rorty (1980).
} 
Among sophisticated epistemic theories of truth, the superassertability theory inspired by Crispin Wright (1992, 1999, 2001 and 2003) ${ }^{2}$ appears to be the most promising formulation. According to the superassertability theory of truth, a statement is true iff it is superassertable in the sense that it possesses indefeasible warrant, i.e., warrant that cannot be defeated by any possible change to the state of one's information. More specifically, as Wright puts the point $(1992$, p. 48$),{ }^{3}$ the superassertability theory of truth holds that a statement is true iff it

... is, or can be, warranted and some warrant for it would survive arbitrarily close scrutiny of its pedigree and arbitrarily extensive increments to or other forms of improvement of our information.

The promise of the superassertability theory of truth, among sophisticated epistemic theories, stems from two virtues it is claimed to have. (1) It appears to be formally legitimate in that it satisfies all the principles thought to constrain truthpredication (more on this later). (2) It spells out the notion 'warranted assertability in ideal epistemic conditions' in precise terms: a statement $\mathrm{P}$ is warranted in this sense if and only if $\mathrm{P}$ possesses warrant that would not be defeated by improvements or enlargements of one's state of information. Due to its precise formulation of 'ideal

\footnotetext{
${ }^{2}$ It is important to bear in mind the extent of Wright's commitment to the superassertability theory of truth. While Wright inspired the superassertability theory, he is not in fact a proponent of it. The superassertability theory is a reductive monistic theory of truth according to which truth is identified with a unique epistemic property, i.e., superassertability (the explanation of which follows in the text). Wright, on the other hand, is the proponent of a pluralistic theory of truth according to which truth is constituted differently from one discourse to another. For Wright, the import of the superassertability criterion is that it furnishes the necessary and sufficient conditions for the truth-aptitude of discourses, in that only a discourse whose statements have superassertable truth conditions qualifies as truth-apt (see his 1992, pp. 33,37 , and 38; the criterion is partially modified in his 2003). Our evaluation of the so-called 'superassertability theory of truth', then, pronounces not upon the theory of truth endorsed by Wright, but rather a sophisticated monistic epistemic theory of truth inspired by Wright, one widely considered to be the most promising epistemic theory of truth currently under consideration.
} 
epistemic conditions', the superassertability theory of truth avoids a couple of the primary defects of other formulations of sophisticated alethic anti-realism: (i) allusions to vague epistemic states of affairs such as the 'end of inquiry', 'limit of investigation', or the like (pace Putnam and Ellis) and (ii) the problematic employment of a certain kind of subjunctive conditional, i.e., one intended to idealize warranted assertability by expanding the scope of our epistemic perspective and/or capabilities (pace Peirce and Misak). ${ }^{4}$

In this paper, I argue that the superassertability theory of truth, while initially promising, encounters an inexorable difficulty. The difficulty is that the superassertability theory of truth, pace other sophisticated epistemic theories of truth, suffers from a kind of instability: it is vulnerable to a similar formal/informal objection that the superassertability theorist herself levels against unsophisticated epistemic theories of truth. A variety of commentators including Horgan (1995) and Van Cleve (1996) have begun formulating an instability objection to the superassertability theory of truth, but fail to spell it out explicitly enough to remove the appearance of spuriousness or of somehow begging-the-question. Sustained analysis reveals that the widely espoused instability objection is firmly grounded in first-person conceivability/possibility evidence.

\section{\$2 An Objection to Epistemic Theories of Truth}

\footnotetext{
${ }^{3}$ For a series of review articles on Wright's (1992), see Philosophy and Phenomenological Research 56(4). For Wright's reconstrual of his (1992) project, see his (2003).

${ }^{4}$ The employment of such subjunctive conditionals is thought to be problematic insofar as it is conflicts with the pragmatic underpinnings of alethic anti-realism - roughly, the dictum that truth is essentially connected with the actual practices of inquiry.
} 
The superassertability theory of truth (hereafter 'ST'), pace other sophisticated epistemic theories of truth, possesses an index free truth predicate. ST, as such, pries truth apart from bare warranted assertability, seemingly permitting it to satisfy a variety of formal and informal principles considered by many (e.g., Wright (1992), pp.72-5, Wiggins (1990), p.210ff and Horwich (1998)), to be minimal constraints on any bona fide truth predicate. By Wright's account (1992, p. 72), these principles include

...the Disquotational Schema... But lurking behind the Disquotational Schema is the more fundamental thesis that to assert is to present as true. Other relevant principles include: that to every assertable content corresponds an assertoric negation; that a content is true just in case it corresponds to the facts, depicts thing as they are, and so on; that truth and warrant are distinct, and...that truth is absolute (there is, strictly, no being more or less true), and more contentiously, that it is stable (if a content is true, it always is).

Conversely, unsophisticated epistemic theories of truth, since they do not detach truth from bare warranted assertability, lack basic formal/informal legitimacy, i.e., they fail to satisfy some subset of the principles invoked by Wright and others as constraining truth-predication. Such a contention is apparently sustained by a virtually universally endorsed line of argument intended to establish the potential extensional divergence of the truth predicate from the warranted assertability predicate that runs roughly as follows. ${ }^{5}$ The predicates 'is true' and 'is warrantedly assertable', it would seem, while possibly normatively coincident, potentially fail to extensionally converge. That is to say, while ' $\mathrm{X}$ is true' and ' $\mathrm{X}$ is warrantedly assertable' may involve the application of the same cognitive norms to $\mathrm{X}$, they potentially apply to different sets of statements since it is possible for a statement $\mathrm{X}$ to be warrantedly assertable at some time and place without 
being true or to be true without being warrantedly assertable at some time and place. For example, consider:

$\left(\mathrm{S}_{1}\right) \quad$ the earth is flat

and

$\left(\mathrm{S}_{2}\right) \quad$ the sun revolves around the earth.

$\left(\mathrm{S}_{1}\right)$ and $\left(\mathrm{S}_{2}\right)$, for all intents and purposes, might have been warrantedly assertable for inhabitants of earth in the year 1050, given the limitations governing inquiry into their truth at such a time and place. Or consider:

$\left(\mathrm{S}_{3}\right) \quad$ Christopher Columbus was the first European to sail the western hemisphere.

While $\left(\mathrm{S}_{3}\right)$ might have been warrantedly assertable for many inhabitants of earth living in the sixteenth century, it is patently false. ${ }^{6}$

Considering its cogency, the question emerges whether it is possible to extend this kind of objection (hereafter 'the legitimacy objection') to sophisticated epistemic theories of truth. One reason for supposing sophisticated epistemic theories of truth such as ST

\footnotetext{
${ }^{5}$ Something like this line of argument is doubtless endorsed by nearly every proponent of the sophisticated epistemic theory of truth.

${ }^{6}$ Wright (1992, pp. 12ff) advances a more ornate variation of the extensional divergence argument. According to Wright, the disquotational schema (DS), when combined with certain platitudes about assertion and negation, reveals the extensional divergence of 'is true' and 'is warrantedly assertable'. The reasoning can be rendered precise: DS logically entails that (1) 'It is not the case that $\mathrm{P}$ ' is true iff it is not the case that $\mathrm{P},(2)$ it is not the case that $\mathrm{P}$ iff it is not the case that ' $\mathrm{P}$ ' is true, and more importantly, (3) it is not the case that ' $\mathrm{P}$ ' is true iff 'it is not the case that $\mathrm{P}$ ' is true, but not (4) it is not the case that ' $\mathrm{P}$ ' is warrantedly assertable iff 'it is not the case that $\mathrm{P}$ ' is warrantedly assertable. Since there are neutral states of information that warrant neither the assertion nor the negation of a declarative clause, there will be cases where 'it is not the case that P' will be unwarranted but 'P' will not be warranted. Moreover, because the
} 
might be vulnerable to this type of objection is that any such theory is a form of monistic epistemic reductivism: it invokes an epistemic constraint on the truth predicate of all discourses. ${ }^{7}$ It has been speculated by a variety of commentators including Horgan and Van Cleve that the line of reasoning aimed at unsophisticated monistic epistemic theories of truth applies ipso facto to any monistic epistemic theory of truth, including sophisticated varieties of it.

To begin to appreciate the import of this supposition, consider the extensional divergence thesis at the basis of the legitimacy objection:

(T) truth is potentially extensionally divergent from warranted assertability.

Naturally, (T) is a special case of a more general thesis, potentially viewed as the basis of an unrestricted legitimacy objection (one that applies to all epistemic theories of truth):

$\left(T^{*}\right)$ the truth predicate is potentially extensionally divergent from any warranted assertability predicate.

If ( $\left.\mathrm{T}^{*}\right)$ is correct, i.e., any statement $\mathrm{X}$ might be true yet not warrantedly assertable in any sense (or vice versa), ${ }^{8}$ truth is not only potentially extensionally divergent from the warranted assertability predicate but also from any idealized warranted assertability

truth predicate in (3) cannot in all cases be replaced by the warranted assertability predicate in (4), the two predicates are potentially extensionally divergent.

${ }^{7}$ That superassertability is an epistemic constraint is indisputable. After all, 'superassertability' refers to indefeasible warrant, and even an indefeasible state of warrant requires in principle accessibility to defeasible evidence. See Wright (1992), p. 77: "Superassertability is ... essentially an evidentially constrained notion - if a statement is superassertable, it has to be possible to gather (defeasible) evidence that it is." This point will be revisited in $§ 5$. 
predicate — any idealization of the form ' $\mathrm{X}$ is warrantedly assertable in ideal epistemic conditions A, B, C...'

\section{§3.0 An Objection to the Superassertability Theory of Truth}

Since $\left(\mathrm{T}^{*}\right)$ is the basis of an unrestricted legitimacy objection, the pivotal question is whether $\left(\mathrm{T}^{*}\right)$ is supportable. At the outset, it requires underscoring that the unrestricted legitimacy objection has prima facie credentials inasmuch as $\left(\mathrm{T}^{*}\right)$ is widely considered to be an essential part of our ordinary understanding of the concept of truth. For many, (T*) is something like a default assumption owing to the apparent normative divergence of truth and idealized warranted assertability, which is thought to imply the potential extensional divergence of these concepts. The normative divergence thesis itself is typically considered to issue from the fact that while idealized warranted assertability is an epistemic norm truth is not. ${ }^{9}$

Substantive support for the unrestricted the legitimacy objection only begins to emerge, though, upon close inspection of the substructure of the formal/informal legitimacy arguments of the kind under consideration. There are two points deserving of examination in this connection. (1) Arguments against the formal/informal legitimacy of epistemic theories of truth seem to issue from first-person conceivability/possibility data: i.e., that it is conceivable, and as a result possible, that a statement might be warrantedly assertable (here and now) yet false. (2) A strengthened conceivability/possibility thesis is compelling and underwrites an unrestricted legitimacy objection: i.e., that it is

\footnotetext{
${ }^{8}$ The parenthetical proviso will hereafter be removed.

${ }^{9}$ That truth is not an epistemic norm is supposed to follow from the recognition that it always is sensible to suppose that a statement might be true yet not X, where X involves the satisfaction of any standard of rational acceptability.
} 
conceivable and as a result possible that a statement might be warrantedly assertable in any sense yet false. ${ }^{10}$

\section{$\$ 3.1$}

For starters, consider (1): the conceivability-possibility basis of legitimacy objections to epistemic theories of truth. Compelling support exists for the view that the extensional divergence thesis at the basis of the legitimacy argument, whatever this thesis turns out to be, must be supported by first-person conceivability/possibility data. The fundamental point is that the primary alternative data - third-person, empirical data - is not available to support $(\mathrm{T}),\left(\mathrm{T}^{*}\right)$, or the like. This certainly seems to be the case with $(\mathrm{T})$ inasmuch as $(\mathrm{T})$ is an extensional divergence thesis regarding one concept whose extension is empirically confirmable ('is warrantedly assertable') and another whose extension is not empirically confirmable ('is true'). ${ }^{11}$ Since (T) is an extensional divergence thesis about two concepts at least one of which is not empirically confirmable, it seems incontestable that (T) itself is not empirically supportable. As a matter of fact, the point seems generalizable (e.g., to $\left(\mathrm{T}^{*}\right)$ ): any thesis to the effect that a concept $\mathrm{X}$ does not apply to the same set of objects as some concept Y, where at least one of the extensions of $\mathrm{X}$ or $\mathrm{Y}$ is not empirically confirmable, is itself not empirically confirmable.

Consider as a case in point how the empirical underdetermination difficulty plagues extensional divergence/convergence assessment of two concepts with

\footnotetext{
${ }^{10}$ For the state of the art on conceivability, possibility and their relations, see Gendler and Hawthorne (2002). In particular, for a discussion of some of important questions relating to the conceivabilitypossibility link, see Chalmers' article in this anthology.
} 
overlapping extensions: 'immeasurably knowledgeable' and 'omniscience' ${ }^{12}$ It is indisputable that while 'Is immeasurably knowledgeable' has an extension that is empirically confirmable, the extension of 'is omniscient' is not empirically confirmable and that the two extensions overlap as long as the extension of the latter concept is not null (since all omniscient beings must be immeasurably knowledgeable). The problem is that it is impossible to empirically confirm that 'is immeasurably knowledgeable' and 'is omniscient' potentially extensionally diverge (that it is possible to be immeasurably knowledgeable without being omniscient) since the extension of the latter concept is itself not empirically confirmable. In other words, without empirical evidence to confirm what, if anything, is omniscient, it cannot be empirically established whether 'is immeasurably knowledgeable' and 'is omniscient' extensionally diverge or converge.

To be sure, it cannot be ruled out that other data might be available in this case. Perhaps, for instance, the extensional divergence of 'is immeasurably knowledgeable' and 'is omniscient' might be supported by what might be called 'indirect' first-person evidence: i.e., reports from language users concerning the differential linguistic usage and inferential role of these concepts. Such a strategy is in principle available to our opponent: insofar as the ordinary linguistic and inferential usage of 'is immeasurably knowledgeable' and 'is omniscient' more or less map onto their actual conceptual and inferential import, the extensional divergence thesis would be indirectly supported. There seems, though, to be two principal problems with this kind of strategy. In the first place, it is not known how closely ordinary linguistic and inferential usage of any concept

\footnotetext{
${ }^{11}$ The extension of 'is true' is not empirically confirmable, at least in any direct or practical sense, since there is currently no evidence available to confirm the truth or falsehood of some statements that fall under its extension (e.g., 'Winston Churchill sneezed 7 times on August 14, 1938').
} 
(including those under consideration) maps onto its actual semantic and inferential import; this is a highly contentious issue among analytic philosophers of language. Secondly, first-person reports of linguistic and inferential usage of concepts are notoriously unreliable (it is often the case that we just don't know how we're using a concept). The implication seems to be, then, that if first-person data is to be wielded in support of extensional divergence theses it is preferable to exploit direct evidence about what seems conceivable (and ipso facto possible) to us rather than indirect evidence about the way we seem to use, apply or draw inferences on the basis of concepts.

In short, it would seem that extensional divergence theses regarding ‘immeasurably knowledgeable' and 'omniscient', 'warrantedly assertable' and 'true', or any other pair of concepts at least one of whose extensions is not empirically supportable, must be supported by first-person conceivability/possibility data. The bottom line is that, among the main alternatives, empirical data is unavailable to support extensional divergence theses of this kind, and indirect first-person data (e.g., first-person reports regarding the differential linguistic and inferential usage of pairs of concepts) provides us with an inadequate and unreliable justification for these theses.

\section{$\$ 3.2$}

Next, consider (2): the appeal of the strengthened conceivability/possibility thesis. Both components of the strong version of the conceivability/possibility thesis are intuitively compelling. The thesis that it is (i) conceivable and as a result (ii) possible that a

${ }^{12}$ In §4 I explain why a similar point applies mutatis mutandis to extensional divergence theses regarding any two concepts (at least one of whose extensions is not empirically confirmable), whether their 
statement might be warrantedly assertable in any sense yet false enshrines a pre-reflective standpoint that is difficult to dismiss.

Regarding (i), there certainly doesn't appear to be a barrier to conceiving of statements that are indefeasibly warrantedly assertable yet false, any more than there is to conceiving of statements that are warrantedly assertable (at some time and place) yet false. Such appears to be a brute fact describing one of our most basic psychological capacities, the boundaries of our conceptual imagination, a fact seemingly confirmable by introspection.

In line with this general standpoint, commentators such as Horgan (1995, p. 130) have proposed brain-in-a-vat thought experiments wherein epistemic subjects might have one or more beliefs that are superassertable yet false. The import of brain-in-a-vat counter-examples of this kind is seriously called into question, though, by a number of complexities concerning the intentionality of brains in vats: e.g., it is not evident whether brains in vats can actually have mental states, beliefs, true beliefs, etc. In conformity with this concern, others have canvassed conceivability counter-examples to ST that do not invoke problematic intentional or doxastic assumptions of this kind. For instance, Putnam's extra-terrestrial scenario seems to fit this mold (2001, pp. 503-4):

(ET) There has existed an extra-terrestrial at some time and place in the universe. In other words, the statement that there has existed an extra-terrestrial $X$ at some place $Y$ and time $Z$ in the universe is true. But this statement is not superassertable since an exhaustive expansion or improvement of our information would not warrant its assertion. Since we cannot travel through all of space and time, no information obtainable could defeat the truth of the statement that there has existed an extra-terrestrial $X$ at some place $Y$ and time $Z$ in the universe. 
Other conceivability counter-examples to ST spring to mind:

(BH) There exists a black hole in the galaxy we currently live. This black hole contains matter (or energy) of type X and amount $\mathrm{Y}$. In other words, the statement that the black hole in our galaxy contains matter of type $X$ and amount $Y$ is true. But this statement is not superassertable since an exhaustive expansion or improvement of our information would not warrant its assertion. Since nothing can escape a black hole - neither matter, light, nor any sort of energy — no information obtainable could defeat the truth of the statement that the black hole in our galaxy contains matter of type $X$ and amount $Y$.

(QM) There exists a quantum particle/wave in the universe. This quantum particle/wave is in position $\mathrm{X}$, has a velocity $\mathrm{Y}$ and momentum $\mathrm{Z}$. In other words, the statement that the quantum particle/wave is in position $X$, has a velocity $Y$ and a momentum $Z$ is true. But this statement is not superassertable since an exhaustive expansion or improvement of our information would not warrant its assertion. Since, pace the uncertainty principle, we cannot measure the position, momentum, and velocity of a quantum particle/wave at the same time, no information obtainable could defeat the truth of the statement that the quantum particle/wave is in position $X$, has a velocity $Y$ and a momentum $Z .{ }^{13}$

On first blush, it is difficult to deny the intuitive force of such conceivability counter-examples to ST. They seem to register the intuition that we can always conceive of a statement that is true yet whose truth is not accessible to ordinary epistemic subjects; or more simply, the intuition that our concept of something $\mathrm{X}$ is not identical to our concept of the totality of the available evidence for and against X. While obviously more needs to be said about these types of examples, and while post-reflection might call them into question (as we will see in $\S \S 4$ and 5), my suggestion will be that it does so only at the cost of relinquishing some fundamental, first-order epistemic and metaphysical beliefs. 
Regarding (ii), to deny that the conceivability of superassertable, false statements is at least some evidence that it is possible for there to be superassertable, false statements, to completely reject the link between conceivability and possibility in this or any other case, looks to be untenable on the face of it. The thesis that there is a defeasible conceivability-possibility link enshrines an intuitively appealing standpoint that seems appreciable independently of any substantive theoretical commitment, and that is currently widely acknowledged among philosophers of diverse orientations (see Gendler and Hawthorne (2002), pp. 5, 6 and 9 and Chalmers (2002), p. 146). More specifically, if I am correct, a defeasible conceivability-possibility link seems indisputable in the area of metaphysics: i.e., that the conceivability of $\mathrm{P}$ is ceteris paribus indicative of $\mathrm{P}$ 's possible existence, where $\mathrm{P}$ is any state of affairs. If nothing else, as I have begun to argue, a defeasible conceivability-possibility link vis-à-vis metaphysics underlies a specific kind of first-order theorizing within semantics.

In the end, then, if the basic tenor of the legitimacy argument has been correctly represented, to defeat its generalization (to all epistemic theories of truth including sophisticated variants such as ST) our opponent must advance post-theoretic grounds to deflate some fundamental intuitions about conceivability and/or the link between conceivability and possibility. Given how firmly entrenched these intuitions seem to be, this is no minor challenge.

\footnotetext{
${ }^{13}$ Needless to say, this counter-example relies on the assumption that $\mathrm{X}, \mathrm{Y}$ and $\mathrm{Z}$ have determinate values, contra Bohr and Heisenberg's Copenhagen interpretation of quantum mechanics.
} 


\section{$\S 41^{\text {st }}$ Reply}

Still, the proponent of ST will attempt to undermine the unrestricted legitimacy objection by taking aim at its evidentiary basis: the strengthened conceivability-possibility thesis. Two principal strategies are available to her for doing so, the first of which I examine in this section and the second of which I examine in the next section.

Firstly, the proponent of ST might try to undermine the unrestricted legitimacy argument by calling into question the conceivability/possibility link at the basis of the strengthened conceivability/possibility thesis, either by disputing the strength of the link or the link tout court. But neither of these approaches looks plausible on the face of it.

For starters, consider the former approach: disputing the strength of the conceivability-possibility link. Along these lines, it might be surmised that if we reject the conceivability-possibility entailment thesis - that the conceivability of a state of affairs P entails the possibility of P's existence - the fact that it might be conceivable for a statement to be true yet not superassertable (as our thought experiments suggest), does not guarantee it is possible for there to be true statements that are not superassertable. Kenyon (1999, pp. 106-7) ostensibly exploits this maneuver when he argues that if truth were indefeasible warranted assertability, the conceivability of true statements that are not superassertable might simply be generated by a dubious prior conception of truth, suggesting that conceivability is not a reliable guide to possibility in such cases.

This strategy is correct as far as it goes, though it doesn't go very far. In the end, Kenyon's line of reasoning misses its target since it fails to furnish any real justification for resisting $\left(\mathrm{T}^{*}\right)$. Undoubtedly, proponents of ST are justified in puzzling about the link 
between conceivability and possibility; conceivability is almost certainly not an infallible guide to possibility. ${ }^{14}$ Such a recognition, though, does little to undermine the import of the conceivability counter-examples to ST. Provided that legitimate conceivability counter-examples to ST have in fact been isolated (a point reexamined in the next section), and assuming conceivability is at least a defeasible guide to possibility, our conceivability scenarios constitute powerful data in support of ( $\mathrm{T}^{*}$ ) (and correspondingly the unrestricted legitimacy argument). In short, insofar as Kenyon's line of argument proposes that $\left(\mathrm{T}^{*}\right)$ could be false even if we can conceive of true statements that are not superassertable, it carries little weight since it does not supercede the fact that conceivability of this kind (provided it is genuine) is a datum that certainly provides substantive support for $\left(\mathrm{T}^{*}\right)$ (and the unrestricted legitimacy argument).

Next, consider the latter approach: dismissing the conceivability-possibility link outright. If conceivability is not even a defeasible guide to possibility the attempt to furnish support for $\left(\mathrm{T}^{*}\right)$ in the form of first-person conceivability/possibility evidence would be futile. The central concern with this tactic is that it is difficult to envisage how the extensional divergence thesis at the basis of the legitimacy argument might be supported without resort to conceivability/possibility evidence. If we are barred from harnessing first-person evidence of what's conceivable and ipso facto possible, it looks to be impossible to furnish support for one theory of truth over another along extensional legitimacy lines. This would seem to follow on the basis of the results of $\S 3$ that demonstrate empirical data is typically unavailable to support extensional

\footnotetext{
${ }^{14}$ After all, as Gendler and Hawthorne (2002, p. 10) point out, the conceivability-possibility entailment thesis seems vulnerable to counter-examples. For instance, it seems conceivable but not metaphysically possible that Hesperus is not Phosphorus and that (on Kripkean grounds) water is not $\mathrm{H}_{2} \mathrm{O}$.
} 
divergence/convergence assessments of theories of truth and indirect first-person data is also ill-suited to this purpose.

The underdetermination difficulty has already been spelled out for the unsophisticated epistemic theory of truth, i.e., the theory that truth is warranted assertability (here and now): third-person empirical data and indirect first-person data are insufficient to determine whether 'is warrantedly assertable' (here and now) is extensional equivalent to 'is true'. Our previous discussion bears out that a similar quandary should plague any other theory of truth, even a theory the truth predicate of which may not extensionally overlap with 'is true'. Consider, as a limiting case, what Van Cleve (1996, pp. 872-3) calls 'the oracular theory of truth', the theory according to which a statement is true iff it is enunciated in one's favoured oracle. If one is prohibited from appealing to first-person conceivability/possibility evidence, how can it be proven that 'is true' and 'is enunciated in one's favoured oracle' are not co-extensive — that a statement can be enunciated in one's favoured oracle and false (and thus that the oracular theory of truth is extensionally illegitimate)? It might appear that third-person empirical data is available to support this extensional divergence thesis, unlike that regarding "is true' and 'is warrantedly assertable' (whose extensions overlap). After all, it has been proven on the basis of third-person empirical evidence that certain biblical claims are false: e.g., claims regarding the age of the universe, the earth, etc. But for all intents and purposes this appearance can be deemed illusory by our opponent since the oracular theorist of truth can claim it is generated by a dubious prior conception of truth, a conception that mistakenly posits fundamental links between truth and current standards of rational acceptability, and from which issues the alleged license for the judgment that 
the relevant biblical claims have empirically been proven false. ${ }^{15}$ Crucially, having severed the conceivability-possibility link, the extensional divergence thesis regarding 'is true' and 'is enunciated in one's favoured oracle' (whether advanced on third-person or first-person grounds) can always be rebuffed by invoking this basic line of reply: the force of the third-person/first-person data supporting the extensional divergence thesis is generated by a dubious prior conception of truth, implying the data does not supply us with any reason for rejecting the oracular theory of truth.

The general lesson, contra our opponent's maneuver in this case, is that extensional divergence theses regarding any two theories of truth must in the first instance be supported by first-person conceivability/possibility data. Severing the conceivability-possibility link, it would seem, precludes arbitrating between alternative theories of truth on the basis of their extensional legitimacy. This means that a defeasible conceivability-possibility link is a regulative assumption of alethic theorizing: conceivability is a reliable guide to possibility all things being equal.

\section{$\$ 52^{\text {nd }}$ Reply}

Secondly, the proponent of ST might try to undermine the unrestricted legitimacy objection by calling into question the veracity of the conceivability counter-examples to ST. She might claim that (ET), (BH), (QM), and similar thought-experiments do not represent legitimate conceivability counter-examples to ST. My claim, in effect, will be that our opponent will be at pains to reject the

\footnotetext{
15 The oracular theory of truth, as a non-epistemic theory of truth, is not logically obliged to posit fundamental connections between truth and current standards of rational acceptability.
} 
veracity of the conceivability counter-examples to ST without relinquishing the epistemological and metaphysical precepts that are supposed to mark out her position.

It might be claimed by the proponent of ST that $(\mathrm{ET}),(\mathrm{BH})$ and $(\mathrm{QM})$ represent legitimate conceivability counter-examples to ST only on the condition that the kind of information available for warranting a statement is constrained in certain ways. But if one relaxes the constraint on the kind of information available for warranting a statement, the conceivability counter-examples to ST might be explained away. For instance, our opponent might suggest, if information possessed by an omniscient being is available for warranting statements then, by all accounts, the statements that there has existed an extra-terrestrial $X$ at some place $Y$ and time $Z$ in the universe, the black hole in our galaxy contains matter of type $X$ and amount $Y$ and that the quantum particle/wave is in position $X$, has a velocity $Y$ and a momentum $Z$ would be superassertable if true. The crucial point is that the apparent failure of these statements to be superassertable despite being true might artificially be generated by what Wright calls "limitations of epistemic opportunity", situations he describes (2003, p. 311) as those in which "knowledge of a truth value may be beyond ... those who, for reasons of spatio-temporal distance, or other accidents of circumstance, are not in sufficiently good position to appraise the statement in question."

Wright is surely correct that the conceivability counter-examples to ST are generated by limitations of epistemic opportunity. One concern, though, is that to expand the scope of information available for warranting statements in the way Wright recommends, to remove all contingencies of epistemic opportunity, does not seem to be a 
maneuver available to the proponent of ST. To make information only an omniscient being could possess available for warranting statements constitutes a seemingly unacceptable abstraction from the situation of an ordinary epistemic subject. Such a strategy, we might say, exploits an account of informational warrant that is unavailable to the proponent of ST or any form of alethic anti-realism (compare Horgan, 1995, pp 131ff and Putnam, 1994a), what can only be described as a realist or God's eye account of informational warrant.

Not surprisingly, Wright has a reply to this well rehearsed line of argument. By Wright's account, the conception of informational warrant illicitly relied on in the attempted rebuttal of the conceivability counter-examples to ST, if it is realist, is only realist in a benign 'common sense' form, of the type Putnam has recently expounded (1994a and 2001). Our opponent, it is claimed, is deploying an account of informational warrant that allows information to warrant a statement that is recognition-transcendent only in practice, i.e., due to practical limitations or contingencies of epistemic opportunity. In other words, the account of informational warrant deployed by our opponent allows for a statement to be warranted only if it would be possible to recognize the evidence for it (or the information relevant to it) provided that all limitations of epistemic opportunity have been eliminated. What is not, on the other hand, being deployed is a malign realist account of informational warrant, one that has truck with what might be called 'in principle recognition-transcendence': the idea that there might be information available for warranting a statement that is in principle impossible to recognize. 
On closer inspection, then, Wright professes to draw a distinction between an innocuous commonsense realism, to which the proponent of ST is committed, in which truth might transcend any and every epistemic opportunity (since these are constrained by practical impediments to epistemic inquiry) and a malign metaphysical realism, to which the proponent of ST is not committed, in which truth might essentially transcend all possible evidence, "no matter what the cognitive starting point from which a thinker went at it" (2003, p. 312). As Wright would have it, metaphysical realism, unlike common sense realism, is off limits to the proponent of ST since it commits itself to the notion that recognition-transcendent truth can arise for some reason other than the unavailability of sufficiently good epistemic conditions. Metaphysical realism, for Wright, is beyond the pale, since it allows for recognition-transcendent truths to issue from necessities of limitation or metaphysical shortcomings that arise due to what Putnam (1994b, p. 487 and 505) describes as "an interface between ourselves and the world".

To be sure, Wright's distinction between commonsense realism and metaphysical realism is far from trivial. What is not evident, on the other hand, is that Wright's distinction can serve the dialectical purposes for which it is intended. In particular, while Wright might be correct that the distinction between a commonsense realist account of recognition-transcendent truth and a metaphysical realist one is significant, he seems wrong in supposing that the commonsense realist account of recognition-transcendent truth is innocuous. In point of fact, from a perspective that is difficult to cast aside, the common sense realist position purportedly underlying ST (and distinguishing it from alethic realism) can be viewed as more or less alethically realist in orientation. Provided 
the alethic realist is a direct realist, i.e., maintains reality can be apprehended directly, she will eo ipso be a commonsense realist in precisely the sense Wright, on behalf of the proponent of ST, claims to be. The alethic realist will concede, in other words, that if we had comprehensive epistemic access to the universe - if we could travel all of space and time, violate all the laws of physics, etc. - then no truth would be beyond our ken. This is to say that the in principle recognitiontranscendence of truth thesis, i.e., the thesis that there is a metaphysical impediment or necessity of limitation that renders truth unknowable, is not an ingredient of the alethic realist position, but of the conjunction of alethic realism and indirect realism. Only if the alethic realist is an indirect realist, someone who maintains that direct apprehension of reality is impossible, does she commit herself to a 'metaphysical realism' according to which truth is in principle recognition-transcendent.

In effect, Wright's misstep can be seen to issue from the conflation of alethic realism and metaphysical realism. Crucially, Wright fails to appreciate that alethic realism is fundamentally a position about truth: i.e., about the nature of the truth conditions of statements and the possibility of their (in practice) recognition-transcendence. It is not, strictly speaking, a metaphysical position, i.e., about the nature of reality, being or existence that our linguistic discourse aims to truly represent. The metaphysical realist position Wright calls 'the interface conception of reality' - the conception of reality according to which facts are essentially inaccessible to any sentient, intelligent creatures, no matter how situated - overshoots the commitments of alethic realism. 


\section{$\S 6$ Conclusion}

In the end, ST seems on shaky ground. The problem is that it is difficult to foresee how ST might escape a legitimacy objection similar to that which ST's proponent levels against unsophisticated epistemic theories of truth, i.e., to the effect that they fail to satisfy some subset of formal and informal principles widely supposed to constrain truth-predication.

If I am correct, the prospects for defusing the unrestricted legitimacy objection look dim. There are two related reasons for this. (1) The legitimacy argument seems to be founded upon first-person conceivability/possibility evidence. Sustained reflection bears out that conceivability/possibility data is needed to support the extensional divergence thesis at the basis of the legitimacy argument (and to arbitrate between different theories of truth on the basis of their

extensional legitimacy) inasmuch as third-person empirical evidence (and indirect first-person evidence) is ill suited to this purpose. (2) A strengthened conceivability-possibility thesis (that it is conceivable and as a result possible for there to be true statements that are not warrantedly assertable in any sense) nullifying ST's extensional legitimacy enjoys a pre and post-theoretic plausibility that is difficult to shake off. In particular, the proponent of ST will be at pains to reject either (i) the defeasible conceivability-possibility link or (ii) the veracity of the conceivability counter-examples to ST underlying the strengthened conceivability-possibility thesis. 


\section{References}

Alston, W. P. (1996) A Realist Conception of Truth. Ithaca: Cornell University Press.

Ellis, B. (1990) Truth and Objectivity. Oxford: Basil Blackwell.

Chalmers, D. J. (2002) "Does Conceivability Entail Possibility?" In Conceivability and Possibility, ed. T. S. Gendler and J. Hawthorne, New York: Oxford University Press, pp. 145-200.

Gendler, T. S. and Hawthorne, J., ed. (2002) Conceivability and Possibility. New York: Oxford University Press.

Horgan, T. (1995) “Wright's Truth and Objectivity”. Nous, 29(1), pp. 127-138.

Horwich, P. G. (1998) Truth, second edition. Oxford: Basil Blackwell.

James, W. (1975) Pragmatism and the Meaning of Truth. Cambridge, Massachusetts: Harvard University Press.

Kenyon, T. (1999) “Truth, Knowability, and Neutrality”. Nous, 33(1), pp. 103117.

Misak, C. J. (1991) Truth and the End of Inquiry: A Peircian Account of Truth. Oxford: Clarendon Press.

Peirce, C. S. (1931) Collected Papers of Charles Sanders Peirce. Ed. C. Hartshorne, P. Weiss, and A. Burks. Cambridge, Massachusetts: Harvard University Press.

Pettit, P. (1996) "Realism and Truth: A Commentary on Crispin Wright's Truth and Objectivity”. Philosophy and Phenomenological Research, 56(4), pp. 883890.

Putnam, H. (1981) Reason, Truth, and History. Cambridge: Cambridge University Press. - (1994a) Words and Life. Ed. J. Conant. Cambridge: Harvard University Press.

- (1994b) "Sense, Nonsense and the Senses: An Enquiry into the Powers of the Human Mind". Journal of Philosophy, 91, pp. 445-517)

- (2001) "When 'Evidence Transcendence' is not Malign: A Reply to Crispin Wright". Journal of Philosophy, 98, pp. 594-600.

Rorty, R. (1980) "Pragmatism, Relativism, and Irrationalism". Proceedings and Addresses of the American Philosophical Association, 53.

Van Cleve, J. (1996) "Minimal Truth is Realist Truth". Philosophy and Phenomenological Research, 56(4), pp. 869-875. 
Wiggins, D. (1980) "What Would be a Substantial Theory of Truth?" In Philosophical Subjects: Essays Presented to P.F. Strawson, ed. Z. VanStraaten. Oxford: Oxford University Press, pp. 189-221.

Wright, C. (1987) Realism, Meaning, and Truth. Oxford: Basil Blackwell.

- (1992) Truth and Objectivity. Cambridge, Massachusetts: Harvard University Press.

— (1999) "Truth: A Traditional Debate Reviewed". In Truth, ed. S. Blackburn and K. Simmons. Oxford: Oxford University Press.

- (2001) "Minimalism, Deflationism, Pragmatism, Pluralism". In The Nature of Truth, ed. M. P. Lynch, Cambridge, Massachusetts: MIT Press, pp. 751-89.

- (2003) Saving the Differences: Essays on Themes from Truth and Objectivity. Cambridge, Massachusetts: Harvard University Press. 